\title{
Defendants with autism spectrum disorders: what is the role of court liaison and diversion?
}

\begin{tabular}{|r|l|}
\hline Journal: & Advances in Autism \\
\hline Manuscript ID & AIA-08-2017-0018.R1 \\
\hline Manuscript Type: & Case Study \\
\hline Keywords: & $\begin{array}{l}\text { Autism Spectrum Disorder, Magistrates Courts, Criminal Justice System, } \\
\text { Psychiatric Reports, Liaison and DIversion, Pre sentence reports }\end{array}$ \\
\hline \multicolumn{2}{|l}{} \\
\hline
\end{tabular}

SCHOLARONE ${ }^{\prime \prime}$

Manuscripts 


\title{
Defendants with Autism Spectrum Disorders: What is the role of Court
} Liaison and Diversion?

\begin{abstract}
Purpose

This paper examines the role of liaison and diversion services working in the lower courts (also known as Magistrates' courts) with regard to autism spectrum disorders (ASD) and their assessment, in particular the role of pre-sentence and psychiatric reports and interviews.

Design

Current practice is described in the lower courts in the context of current legislation and procedures.

Findings

When writing reports there is a need for expertise to offer an opinion on future risk, disposal and what needs to be in place to support people with autism spectrum disorders. No assumptions should be made when reporting on the basis of an ASD diagnosis alone and each case must be assessed on its individual merits while ensuring that individual human rights are protected.

Originality

There is currently a sparse literature examining ASD in court settings. This paper seeks to clarify current practice.
\end{abstract}

\section{Keywords}

Autism Spectrum Disorder - Criminal Justice System - Liaison and Diversion - Magistrates Courts

- Psychiatric Reports - Pre-sentence reports 


\section{Introduction}

Within this paper autism spectrum disorders (ASDs) are defined as meeting the clinical criteria that are outlined in item F84 in the International Classification of Diseases (ICD-10, World Health Organization, 2016), and in the DSM-V definition. The latter definition lists two main criteria that incorporate the three core features listed in ICD-I0. These are deficits in:

\section{1: Social Communication \& Social Interaction; \\ 2: Restricted \& repetitive behaviour, interests or activities.}

There have been a number of new policy initiatives over the last few years relating to autism. In 2009, the Autism Act was introduced as the first disability-specific legislation in the UK. This set out key objectives to deliver a national autism strategy for England (Fulfilling and Rewarding Lives: The Strategy for Adults with Autism in England, 2010), with the following aim:

\section{"All adults with autism are able to live fulfilling and rewarding lives when society accepts and} understands them. They can get a diagnosis and access support if they need it, they can depend on mainstream public services in treatment of these individuals helping them to make the most of their

$$
\text { talents” (McCarthy et al 2015). }
$$

It was an expectation that criminal justice system (CJS) workers such as police officers, court and prison staff, should have a working knowledge of ASD. However, in reality the context was one in which there was not only a widespread lack of awareness, but also deficiencies in ASD screening and diagnostic services across the CJS (Chaplin and McCarthy, 2014). This paper examines the role of liaison and diversion services in the lower (Magistrates') courts in England and Wales, and the role of pre-sentence and psychiatric reports and interviews, as regards ASD.

There is little available evidence regarding the prevalence of ASD within the criminal justice system and its pathways, or regarding its association with offending behaviour (Pearce et al., 2016; Allely, 2015). There is no consensus as to rates of ASD in the CJS, particularly given the fact that they are not consistently identified. For example there is some evidence to suggest that people with autism are over-represented in prisons (Underwood et al., 2016), however varying prevalence rates have been reported in specific prison populations of between $0.93 \%-4.4 \%$ (Robinson et al 2012, Fazio et al, 2012). By contrast, a systematic review by King and Murphy (2014) reported that people with ASD are not over-represented in the CJS. What is clear, however, is that there is little published data in England and Wales regarding people with ASD in the CJS, with court settings representing a particularly under-researched and under-reported area. Prevalence estimates for people with ASD appearing in court are difficult to establish, particularly given the context in which there has been 
limited evaluation of current interventions and services, and the developmental nature of existing liaison and diversion services in England and Wales (Srivastava et al, 2013). What evidence we do have comes largely from biased samples, such as those who are referred because of mental health issues, or those who are already known to forensic services (King and Murphy, 2014). Therefore, improved services with access to specialist clinicians are required to identify new cases.

\section{Current Legislation and Practice Guidance}

In the courts, agreed procedures are applied to consider fitness to plead (also known as competence to stand trial in some other jurisdictions) in accordance with legislation ${ }^{1}$, and with criteria that have been set out through case law (Crown Prosecution Website, 2017; Mudathikundan et al., 2014). For those defendants whose cases will subsequently be tried within the upper (Crown) Courts, the core criteria have been established in $R v$ Pritchard (1836), as subsequently operationalised by $R v M$ (John) (2003). They require that defendants are able to:

- Understand the charges they are facing;

- Decide whether to plead guilty or not;

- Exercise the right to challenge jurors;

- Instruct their legal representatives;

- Follow the course of proceedings;

- Give evidence in their own defence.

In order to meet these criteria, vulnerable defendants may require additional support. This can be provided either by adapting the environment, or by offering direct assistance such as the use of an intermediary (CPS website, 2017). The need for equity for people with autism in the courts is well established (Department of Health, 2009, Equality Act, 2010), and their overall management should proceed within the provisions of article 6 of the European convention on human rights, which includes five basic rights for all defendants to ensure they have access to a fair trial. These rights are as follows:

a) To be informed promptly and in detail, in a language which the defendant understands, of the nature and cause of the accusation that has been made;

\footnotetext{
${ }^{1}$ The Criminal Procedure (Insanity) Act 1964, as amended by the Criminal Procedure (Insanity and Unfitness to Plead) Act 1991 and by various sections of the Domestic Violence, Crime and Victims Act 2004
} 
b) To have adequate time and facilities to prepare a defence;

c) To defend himself/herself in person or through legal assistance of his/her own choosing or, if the defendant has insufficient means to pay for legal assistance, to be given it free when the interests of justice so require;

d) To examine or have examined witnesses against him and to obtain the attendance and examination of witnesses on his behalf under the same conditions as witnesses against him;

e) To have the free assistance of an interpreter if the language used in court cannot be understood.

Although these rights have been incorporated into domestic legislation via the Human Rights Act 1998, it is still the case that vulnerable defendants often do not have an adequate level of access to some of the special measures that can be made available when required. This can be because of persisting difficulties with case identification and the availability of professionals with suitable levels of expertise. This can have a significant effect on the overall process (e.g. by impacting upon the quality of court reports provided, or the awareness of types of reasonable adjustments required to support a person with autism in court). In general terms, better quality information needs to be made available to those who are responsible for sentencing and disposal. While decisions are often made in the public interest to ensure safety, it is also in the public interest not to incarcerate people when other less restrictive alternatives may exist, and where any threat to public safety can be safely and appropriately managed in other ways (Department of Health, 2009). An approach to sentencing mentally disordered offenders in England and Wales has been set out in $R v$. Birch [1990], with community sentencing options being subject to a number of considerations, including:

- The nature of the offence;

- history of offending;

- the presence of mental illness;

- $\quad$ substance misuse;

- capacity to consent;

- issues of vulnerability.

Guidance from the Ministry of Justice (Ministry of Justice, 2011) acknowledges that people with autism can have a wide variety of abilities. It is important to ensure that interviews are conducted sensitively, and for that reason guidance is in place to assist interviewers in applying a measured approach to witnesses, as outlined below: 
- The interviewer should:

- try to be calm, controlled and non-expressive;

○ provide a stable environment (e.g. using the same room for multiple interviews);

- The witness may:

○ Be frightened of emotion or shouting;

- Be fearful of unfamiliar stimuli, including noise, colour and people new to them;

○ not like people to come too close to them;

○ not like to make direct eye contact.

(Ministry of Justice (MoJ), 2011)

\section{Role of Liaison and Diversion Services Screening}

Liaison and diversion services have developed in England and Wales over the last few decades (James, 2010, Srivastava et al., 2013), with a remit to identify and support people who present with vulnerabilities (including mental health and/or substance misuse problems, learning disabilities or other vulnerabilities) when they are in the criminal justice system. These services currently cover just over half of the population of England, although there is a clearly described aim to continue to progress with further service rollout in time (NHS England website, 2017). Within the context of these national developments, , assessments for autism currently vary considerably across geographical locations. These assessments depend upon the availability of services, specific expertise, and local policy arrangements.

After an individual has been brought to court, they will often be assessed by the court liaison and diversion team if they are suspected of having a mental health issue, or a neurodevelopmental disorder including intellectual disability or autism. However, reliable screening for autism, or for any other mental disorder, has yet to be developed and implemented in court settings, and it is therefore likely that many cases are missed. Although the NICE guidelines recommend the Autism Qutient-10 (AQ10) (National Institute for Health and Clinical Excellence (NICE), 2014) to screen for autism in community settings, research within CJS however, suggests this instrument is over-inclusive, often identifying autistic traits in people who do not, in reality, present with autism spectrum disorder (McCarthy et al , 2015). Therefore, even if screening were to be introduced across the board, limitations to identification would still exist. Another opportunity to make a fuller assessment, and to explore diagnostic questions further, can include a referral to the psychiatrist working within court liaison and diversion services. Within a court environment, the use of gold-standard instruments such as the Autism diagnostic observation schedule (ADOS-G) (Lord et al, 1989) and Autism diagnostic interview-revised (ADI-R) (Lord et al 1984) may be difficult to administer, due to time and capacity constraints of the court and its staff, but if they are required the further instruction of an expert witness can take place. For those assessing for autism, the Diagnostic Interview Guide for the Assessment of 
Adults with Autism Spectrum Disorder (ASD) - designed and produced by the Royal College of Psychiatrists (Berney et al, 2011) - offers a framework for the clinical interview for both the person and carers.

\section{Assessment and Advisory Role}

The use of an enhanced cognitive interview (ECI) is advocated for the majority of vulnerable defendants or witnesses; however there may be an issue that some people with autism might find this approach difficult, particularly those who are unable to change their perspective (MoJ, 2011). It is based on the cognitive interview (CI) which is a phased interview to improve witness memory performance and is conducted in four phases, where the aim is to:

1) Report everything;

2) Mentally reinstate the context;

3) Recall events in a variety of different temporal orders;

4) Change perspective.

In real-life interview situations within the CJS, CI was found to lack effective interpersonal communication, so the ECI was then developed based on memory and the social psychology of communication research and introduced additional techniques such as transfer of control and witnesscompatible questioning (MoJ, 2011, See appendix H, p186 for further details). Although any interview around offending will take into account issues that predict offending such as poor socioeconomic status, it is the circumstances in which an alleged offence takes place or the motivation for it which may differ for people with ASD that will also be examined. In the past, the core features of ASD have been put forward as a potential reason as to why this group may offend. Some of the factors that have been put forward that may increase risk, but are not typical of general offender populations, include impaired theory of mind which may limit understanding of and interpreting everyday situations, being vulnerable to exploitation from others, particularly those of a passive nature. Social naiveté, such as understanding of rules and meaning of everyday social situations such as relationships and mistaking social cues and becoming over familiar where there is no reciprocal signs or cues. Some may copy acitons of those in their company or that they may have seen elsewhere or on $\mathrm{TV}$, the reality of this may be to cause offence and have a negative consequences. Other autistic people, may become anxious in certain situations or circumstances e.g. people breaking rules often the reaction to this may be out of proportion to how others react e.g. chastising someone repeatedly who is eating on public transport. Other factors that may be an issue include impulsivity or negative reaction to problems with understanding, or having difficult negotiating, which may lead 
to frustration and aggression, or obsessional interests. In turn, this may lead to offending behaviour, with limited understanding of the full consequences of their actions, particularly in areas such as cybercrime (Archer and Hurley; 2013 and King and Murphy, 2013). As well as looking at offending behaviour, it is also important to ensure how the individual with ASD presents, and whether their behaviour is interpreted correctly. For example, behaviour such as anxiety may be wrongly perceived as threatening and may reulst in interviews being terminated prematurely, or even in force being used in some extreme situations. Good or adequate language skills can, at times, be misinterpreted to assume the person is not vulnerable as they actually are, and as a result more details and reasonable adjustments, such as use of intermediaries and sensory breaks, will not be considered. Due to communication misunderstandings, some people with ASD may also unwittingly incriminate themselves (Archer and Hurley; 2013).

\section{Reports and Diagnostic Assessment}

Following assessment, reports can be provided to the lower courts in a number of ways. Increasingly, information is provided by nursing staff, or voluntary sector providers, in short reports that are mainly focused on providing background information and context. For more complex cases, psychiatric reports can either be provided as part of the liaison and diversion service, or via the instruction of an expert witness. The defence or the prosecution, or the court itself, can instruct these reports, which are often focused on psychiatric defences such as fitness to plead, or disposal arrangements such as hospital or community orders. After being instructed to provide a report, the nature of expert evidence, including the duty the expert has to the court and the prescribed content of their report, is set out in the Criminal Procedure Rules 2015. Part 19.4 of these rules requires that reports include the following information:

- Qualifications, relevant experience and accreditations;

- Literature and information the expert has relied upon when writing their report;

- Contain a statement setting out the substance of all facts given to the expert which are material to the opinions expressed in the report, or upon which those opinions are based;

- Make clear which facts are within the expert's own knowledge (e.g. mental state examinations);

- Say who carried out any examination, measurement, test or experiment which the expert has used for the report;

- Where there is a range of opinion on the matters dealt with in the report, summarise the range of opinion, and give reasons for the expert's own opinion;

- If the expert is unable to give an opinion without qualification, state the qualification; 
- Contain a summary of the conclusions;

- Include a statement that the expert understands their duty to the court, and that they have complied with, and will continue to comply with, that duty;

- Contain the same declaration of truth as a witness statement.

Within the interview, the nature and circumstances of the alleged offence should be considered, along with the role of any mental health problem or developmental disorder such as autism. Depending on the instructions, context, and agreed remit, reports can offer advice in a number of areas, including fitness to plead, mental state at the time of the offence and at interview, and any association between the offence and the defendant's mental condition. Disposal recommendations can include mental health disposals under the Mental Health Act 1983, such as a Hospital Order (Section 37), or community orders provided under the Criminal Justice Act 2003.

When providing assessments and making recommendations for people who present with autism, the mental state examination should take into account key presenting symptoms and core deficits (e.g. social communication, interaction and restrictive interests) and consider their role, if any, in the offending behaviour.

This is usually the starting point for clinicians to understand any relationship between ASD and offences. However, often autistic people will not associate these core deficits with getting into trouble or offending. Studies where people with ASD have been asked about triggers to their behaviour, they may recognise some change in themselves or their circumstances and report feelings of stress and excitement (Helverschou et al, 2015) or being upset, agitated, having bad habits, beg impulsive, family or work problems or having mental health problems (Allen et al, 2008). To detect and comment on the needs and disposal of defendants with ASD appearing before the court, it is good practice to have a psychiatrist with experience in ASD and other common neurodevelopmental disorders such as intellectual disability and attention deficit and hyperactivity disorder .

\section{Pre-sentence reports}

There are three types of pre-sentence report, for the first two an adjournment will be requested. These will assess risk likelihood of cooperation and culpability.

- Standard Delivery report for complex cases and where there is a high risk of harm. The report will include a risk assessment and detailed sentence plan. Interviews are up to two hours long and take place at the probation office.

- Fast Delivery report where there is medium risk 
- Stand Down (Oral) report is a verbal report completed on the day at court. For low risk and some first offenders.

The function of the report is to whether there are mitigating or extenuating circumstances or whether there is a previous history that might increase risk and indicate the recommendation of harsher sentences to reflect this. Within the meaning of section 158 of the Criminal Justice Act 2003, these reports are meant to:

- Assist the court in determining the most suitable method of dealing with the offender;

- Contain information as to such matters, presented in such manner, as may be prescribed by rules made by the Secretary of State.

When interviewing someone with autism as part of a pre-sentence report, it is necessary to have knowledge of the condition and how this influences future risk and what might be done to mitigate this.

Having been referred for pre-sentence reports, and when it is known that the person is vulnerable, or a potential risk to public safety, or both, there are a number of things that should be considered during the subsequent interview:

- The individual is likely to be less able to understand and cope with the requirements of the court process;

- There is a need to identify behaviours associated with autism, so that odd behaviour is not interpreted as being rude of threatening;

- They may be over-compliant with the process;

- They may have a fear of strange situations, places and/or authority;

- There are likely to be communication problems.

MoJ Sentencing (2011)

Below is a short example of a case study illustrating the court process and fitness to plead.

\section{Case study}

Alf is a 30-year old man with ASD who has stabbed his flatmate after believing he was colluding with the neighbourhood children by allowing them to play football at the front of the house, which was not the case. Following a number of heated exchanges and difficulty coping with the noise of the ball banging against the wall, he attacks his flatmate by punching him and saying "make them stop". Whilst being assessed in Court, he refuses to have someone represent him or to answer questions 
believing he had done nothing wrong. He believes his flatmate should be the one being sent to court as he let children play outside the house when there is a sign stating clearly that ball games on the green and in the close are strictly forbidden. Any attempts to interview or engage in reciprocal conversation are not possible as he is clear about what he has done and keeps repeating that he stabbed his flatmate who was breaking the rules. He is happy to tell people what happened but refuses to be cross examined as he says it is unnecessary.

The case would need to be sent to the Crown Court. There a Judge would determine his fitness to plead. Subsequently, a jury would need to find that he had done the Act he is accused of. Following this, the following disposals can be applied for those not fit to plead.

- hospital order

- supervision order

- absolute discharge

If a defendant is found fit to plead then the court will proceed as normal. However if the defendant is found unfit to plead, then there is a "trial of the facts" in which it is established whether the defendant has done the act, rather than establishing whether they are guilty or not guilty.

\section{Summary and Conclusion}

It remains the case that courts may not employ specialist assessment as they fail to identify and understand the need, and the difficulties, that people with ASD exhibit when they appear in court. The introduction of specialist staff, or specific liaison and diversion services, for people with ASD has the potential to improve services for people with ASD, helping them to understand and navigate the court process. It could also assist the court in understanding their needs, and it can inform subsequent sentencing and disposal outcomes.

Although there is evidence that liaison and diversion services are identifying cases already known to hospital and forensic services, there is need for specialist services to advise the court on risk, care packages and interventions that can mitigate perceived risks that might lead community sentence options. There is also a need to identify new cases and to ensure full assessment. If we do not increase awareness on ASD then we will continue to miss such cases within the CJS, and services will not be able to respond to them in an appropriate manner. There is a need for a range of expertise, so that court staff are aware of the needs of people with autism and other vulnerable defendants. Clinical expertise should be available to provide information, and expert opinions may be instructed to 
facilitate an appropriate outcome following the court process, end to ensure that individual human rights are protected.

\section{References}

Allely, C.S., 2015. Experiences of prison inmates with autism spectrum disorders and the knowledge and understanding of the spectrum amongst prison staff: a review. Journal of Intellectual Disabilities and Offending Behaviour, 6(2), pp.55-67.

\section{Alleyn}

Archer, N., \& Hurley, E. A. (2013). A justice system failing the autistic community. Journal of Intellectual Disabilities and Offending Behaviour, 4(1/2), 53-59.

Berney T (2011) the Diagnostic Interview Guide for the Assessment of Adults with Autism Spectrum Disorder (ASD). London, Royal College of Psychiatrists

Chaplin, E. and McCarthy, J. (2014), "Autism spectrum disorder and offending - a UK perspective", Autism Spectrum Quarterly, pp. 14-16

Criminal Justice Act 2003 c44 UK Public General Acts

Criminal Procedure Rules (2015) What's New? Criminal Procedure Rules

https://www.justice.gov.uk/courts/procedure-rules/criminal [Accessed 16.08.2017]

Crown Prosecution Website (2017) http://www.cps.gov.uk/ [Accessed 09.08.2017]

Department of Health (2009). The Bradley Report. Lord Bradley's review of people with mental health problems or learning disabilities in the criminal justice system. London, Department of Health. Crown Prosecution Service website. (2017). Mentally disordered offenders. Available at: http://www.cps.gov.uk/legal/1_to_o/mentally_disordered_offenders/\#b03 [Accessed 09.08.2017] Equality Act (2010) c15 UK Public General Acts Fazio, R.L., Pietz, C.A. and Denney, R.L., (2012). An estimate of the prevalence of autismspectrum disorders in an incarcerated population. Open Access Journal of Forensic Psychology, 4, pp.69-80. 
James D (2010) Diversion of mentally disordered people from the criminal justice system in England and Wales: An overview. International Journal of Law and Psychiatry 33: 241-248.

Helverschou, S.B., Rasmussen, K., Steindal, K., Søndanaa, E., Nilsson, B. and Nøttestad, J.A., 2015. Offending profiles of individuals with autism spectrum disorder: A study of all individuals with autism spectrum disorder examined by the forensic psychiatric service in Norway between 2000 and 2010. Autism, 19(7), pp.850-858.

Human Rights Act 1998 c42 UK Public General Acts

King, C., \& Murphy, G. H. (2014). A Systematic Review of People with Autism Spectrum Disorder and the Criminal Justice System. Journal of Autism and Developmental Disorders. DOi:

10.1007/s10803-014-2046-5

Lord, C., Rutter, M., Goode, S., Heemsbergen, J., Jordan, H., Mawhood, L. and Schopler, E. (1989), "Autism diagnostic observation schedule: a standardized observation of communicative and social behavior", Journal of Autism and Developmental Disorders, Vol. 19 No. 2, pp. 185-212.

Lord, C., Rutter, M. and Le Couteur, A. (1994), “Autism diagnostic interview-revised: revised version of a diagnostic interview for caregivers of individuals with possible pervasive developmental disorders", Journal of Autism and Developmental Disorders, Vol. 24 No. 5, pp. 659-85.

Mental Health Act 1983 c20 UK Public General Acts

Ministry of Justice (2011) Achieving Best Evidence in Criminal Proceedings Guidance on interviewing victims and witnesses, and guidance on using special measures

McCarthy J, Chaplin E, Underwood L, (2015),"An English perspective on policy for adults with autism", Advances in Autism, Vol. 1 Iss 2 pp. 61 - 65:http://dx.doi.org/10.1108/AIA-08-2015-0011

McCarthy J, Chaplin E, Underwood L, Forrester A, Hayward H, Sabet J, Young S, Asherson P, Mills R \& Murphy D. (2015). Screening and diagnostic assessment of neurodevelopmental disorders in a male prison. Journal of Intellectual Disabilities and Offending Behaviour, 6(2), 102-111.

Mudathikundan, F., Chao, O., \& Forrester, A. (2014). Mental health and fitness to plead proposals in England and Wales. International Journal of Law and Psychiatry, 37(2), 135-141.

NHS England website. (2017). About liaison and diversion. Available at:

https://www.england.nhs.uk/commissioning/health-just/liaison-and-diversion/about/ - [Accessed on 09.09.2017] 
NICE (2014), Autistic Spectrum Disorders in Adults, National Institute for Health and Clinical Excellence, London.

Pearce, H., Pearce, H., Berney, T. and Berney, T., 2016. Autism and offending behaviour: needs and services. Advances in Autism, 2(4), pp.172-178.

$R v$ Birch [1990] 11 Cr App R (S) 202

R v M (John) [2003] EWCA Crim 3452 Court of Appeal

R v Pritchard (1836) 7 C\&P 303

Robinson, L., Spencer, M.D., Thomson, L.D., Stanfield, A.C., Owens, D.G., Hall, J. and Johnstone, E.C., (2012). Evaluation of a screening instrument for autism spectrum disorders in prisoners. PLoS One, 7(5), p.e36078.

Senior Courts of England and Wales. (2015). The Criminal Procedure Rules. Statutory Instrument no. 1490.

Srivastava, S., Forrester, A., Davies, S., \& Nadkarni, R. (2013). Developing criminal justice liaison and diversion services: research priorities and international learning. Criminal Behaviour and Mental Health, 23(5), 315-320.

Underwood, L., McCarthy, J., Chaplin, E., Forrester, A., Mills, R., \& Murphy, D. (2016). Autism spectrum disorder traits among prisoners. Advances in Autism. 